\title{
8 Informality and the dynamics of the structure of employment
}

\author{
James Heintz
}

A great deal of effort has gone into measuring informality, documenting working conditions, and understanding the constraints that informal workers face. Apart from broad trends, less attention has been paid to documenting how informal employment changes over time. One of the central policy debates centres on the need to transform informal employment to improve outcomes for working women and men. Is there a need for formalisation, what does it mean, and how might it be achieved? But discussions of formalisation typically view informal employment changing incrementally - moving specific individuals, jobs or enterprises closer to formality. One way of thinking about this process is to imagine a continuum of informality. Formalisation therefore requires making marginal changes to employment arrangements along this continuum to move existing forms of paid work towards greater formality.

But does formalisation (or informalisation, the expansion of informal employment, for that matter) happen incrementally? Or do the important shifts in informality represent larger disruptions of the status quo - through structural transformations of the economy? In the 1950s, South Korea had a similar level of development, demographic structure, and patterns of employment as Kenya. Agriculture was a large sector, small-scale self-employment was common (i.e., there was a sizeable informal sector), and formal wage employment was relatively limited. In a matter of a few decades, this all changed. Formal wage employment expanded rapidly with the process of industrialisation. Informality declined, particularly informal self-employment. Informality eventually took on a different form and began to be associated with wage employment. Specifically, after the 1997 East Asian economic crisis, the rapid increase in non-regular wage employment was a central concern - rather than the persistence or growth of an informal sector consisting of small-scale enterprises. These changes did not happen piecemeal, through the formalisation of individual employment arrangements. They occurred because of a structural transformation of the Korean economy. Kenya did not experience a similar structural shift. Informal self-employment in small, household enterprises and farms continues to characterise much of the employment in Kenya.

The classic Kaldorian explanation of why employment is transformed during the process of development was based on the experience of industrialisation in high-income economies of the Global North and can be applied, to some extent, 
to the newly industrialising economies in East Asia that experienced a similar transformation in the last decades of the twentieth century. This narrative of structural change goes something like this: Labour moves out of small-scale agriculture and into other sectors, most importantly manufacturing and other types of industrial production. Due to advances in production methods and technology, labour is more productive in these industrial sectors than in traditional agriculture. These productivity gains translate into economic growth, as an industrialising country is able to produce more goods and a more diverse array of products. As more labour moves out of traditional agricultural activities and into industrial production, the average productivity of the economy grows.

Higher levels of labour productivity also support improvements in living standards. When incomes rise, households tend to spend a smaller share of their total income on food and start buying other things. People are able to purchase the manufactured goods produced, leading to further industrialisation. Demand for services also rises. This supports an expanding service sector and new employment opportunities. Within this narrative of industrialisation, the process of economic development is therefore associated with a transformation of the structure of employment, with labour moving out of agriculture and into industrial production and a growing service sector. The spatial distribution of labour also changes. The movement out of agriculture is associated with the urbanisation of the workforce.

Industrial production is typically associated with economies of scale. When economies of scale exist, the average productivity of industrial activities increases as firms become larger and larger and as economies diversify, producing spill-over benefits from one sector to another. Workers increasingly specialise in specific tasks and focused activities. Team production can be more efficient than having each worker involved in all stages of the production process. Larger factories, with specialisation and joint production, yield rapid increases in productivity.

Larger firms require larger workforces. How do these companies hire the labour they need? One option would be to treat workers as self-employed, independent contractors and negotiate individual contracts with each worker, outlining the specific tasks that need to get done. Indeed, this was done in the putting out system of the early factories in Britain and in the US when the productive contribution of individual workers could be identified and joint, or team, production was not well established. However, as production systems became more complex, constantly negotiating and re-negotiating individual contracts for an expanding workforce would have been costly and taken time. Plus, it adds a layer of uncertainty. What if the company cannot find the right person to do a task that is essential to production? An alternative solution is to hire workers as paid employees who show up every day and perform a standard set of tasks. As firms get larger, this employment arrangement is more efficient. The process of industrialisation, therefore, is associated with more of the workforce being employed as paid employees.

The emergence of a wage labour force transformed the way societies, and economists, have come to think about labour markets. When wage labour is the 
predominant way that paid employment is organised, the labour market can be thought of as operating though the interaction of labour demand (i.e., employers or firms hiring employees) and labour supply (i.e., wage workers looking for jobs that match their skills and experience).

This pattern differs from that observed in economies with a large informal sector in which self-employment accounts for a large share of employment. For instance, three-quarters of all workers in Africa and two-thirds of all workers in South Asia are self-employed (ILO 2018a; Bonnet, Vanek and Chen 2019). Indeed, 44 per cent of all workers globally are self-employed, though the share of self-employment in total employment varies widely across countries (ibid.). For workers in self-employment, the distinction between labour demand and labour supply is blurred, and the standard model of a wage labour market does not apply. A different model for these self-employment-dominated labour markets is required - one that sees the demand for the labour of the selfemployed coming, not from profit-maximising employers, but from the final demand for the services or goods that informal self-employed workers produce.

When the countries of the Global North were industrialising, employees in factories often organised themselves to bargain for improvements in working conditions, either as unions or other types of worker organisations. Negotiations involved hours of work, safety concerns, wages, hiring and firing practices, and other aspects of overall working conditions. Collective action among workers results in the regulation of labour markets, setting minimum standards and basic levels of decency. These labour standards eventually found their way into national labour laws that spell out a range of social protections for working people. In other words, paid employment becomes formalised through a process of collective action linked to the transformation of these economies.

For these reasons, the process of economic development has been accompanied by a far-reaching transformation of the structure of employment. To summarise, the stylised narrative - based on the historical trajectory of countries that have gone through, at least to some degree, a process of industrialisation - is as follows. There is a movement of labour out of agriculture and into industrial and service jobs. Many workers experience improvements in their standards of living. Working as paid employees replaces forms of selfemployment as the dominant employment arrangement. And, as wage employment expands, these employment relationships become increasingly regulated and formalised through processes of collective action at various levels - the firm-level, the industry-level, and the national-level. Formalisation, therefore, has been a result of structural changes in economies.

However, formal wage employment itself is subject to change and can become informalised, as discussed earlier in the case of Korea. Global integration and technological changes often redistribute power away from labour and towards capital, or away from employees and towards employers. These changes in the balance of power have been associated, in many cases, with a roll-back in worker protection and deregulation of labour markets. One outcome has been the informalisation of wage employment in countries where wage employment dominates. 
Further advances in technology and the organisation of our economies will continue to shift transactions costs and redefine employment arrangements. One reason, but not the only reason, for the emergence of large-scale wage employment during a process of industrialisation is that organising employment relationships this way, as opposed to hundreds or thousands of individual contracting arrangements with self-employed individuals, allows for specialisation and realisation of economies of scale. However, in recent years, the costs of contracting with individual self-employed workers have fallen with the emergence of new technologies. Increasingly, large firms can mobilise the labour they need without entering into wage employment contracts. The employment model of Uber (and other parts of the "gig economy" and the global sourcing of "crowd work") is a case in point. These practices may come to alter how labour markets evolve and the nature of future transformations in the structure of employment - with important implications for how we think about questions of informality and formality.

Given the importance of structural change, as well as structural differences in labour markets, it is not surprising that there are different typologies for thinking about informality in developing and developed countries. Why is it difficult to come up with a unifying framework? Because the structures of the economies are different, and informality is not a continuous variable. For these reasons, trying to develop a unified framework without an appreciation of structural differences across countries' economies is challenging and perhaps misguided.

This points to an important area of research - understanding the relationship between informality and structural change. In this regard, the economic history of informality is important - but, with few exceptions, research in this area is largely missing (see Harriss-White in Chapter 2 and Breman in Chapter 1, for examples of such exceptions). It has a lot to contribute to our understanding of labour market structure and how it changes over time. In the nineteenth century, many western high-income countries had structures of employment with widespread informality. It would be interesting to explore what these looked like and how this structure changed over time. ${ }^{1}$

This discussion has important policy implications. The formalisation debate is flawed because it considers the path to formality to be an incremental one, based on individual enterprises or jobs and the idea that informality can be thought of as a simple continuum. There are research projects that try to document how informal enterprises can move up - from very micro, to micro, to small, then medium-scale enterprises. But does this happen in isolation? The ability of one firm to formalise may depend on what is happening to other enterprises in the economy. We need more work in this area to truly understand the dynamics of informal employment.

\section{Note}

1 Examples of these processes from the US include Cobble and Vosko (2000) and Montgomery (1980). 